Article

\title{
Enhanced Protection against Influenza Virus Infection with Dispersion Controlled Lactic Acid Bacteria Powder
}

\author{
Takumi Watanabe ${ }^{1,2, *}$, Kyoko Hayashi ${ }^{2}$, Isao Takahashi ${ }^{3}$, Makoto Ohwaki ${ }^{4}$, Tatsuhiko Kan ${ }^{1}$ \\ and Toshio Kawahara ${ }^{5, *}$ \\ 1 Bio-Lab Co., Ltd.; t.watanabe@bio-ken.jp \\ 2 Graduate School of Engineering, Chubu University; kyhayashi@cronos.ocn.ne.jp \\ 3 ICAM Co., Ltd.; takahashi-i@icam.co.jp \\ 4 Non-Profit Organisation, The Japanese Association of Clinical Research on Supplements; ohwaki@jacrs.org \\ 5 College of Life and Health Sciences, Chubu University; toshi@isc.chubu.ac.jp \\ * Correspondence: t.watanabe@bio-ken.jp; Tel.: +81-42-978-7208
}

\begin{abstract}
We evaluated the change in water dispersibility of lactic acid bacteria (LAB, Enterococcus faecalis $\mathrm{KH} 2$ ) upon powderization and its influence on their efficacy. When cultured LAB are washed, heat-killed, and powdered, adhesion between $L A B$ occurs and they form aggregation (non-treated LAB, n-LAB). However, a dispersed LAB (d-LAB) powder with less aggregates can be prepared by treating them with a high-pressure homogenizer and adding an excipient during powdering. $n-L A B$ or $d-L A B$ was administered to mice and the Peyer's patches in the small intestine were observed. $n-L A B$ administration showed a high amount of aggregated LAB drifting in the intestinal mucosa, whereas d-LAB reached the Peyer's patches and was taken up into the Peyer's patches. Evaluation in a mouse influenza virus infection model showed that d-LAB was more effective than n-LAB in influenza yield of bronchoalveolar lavage fluids (BALFs) on day 3 post-infection, neutralizing antibody titers of sera and influenza virus-specific IgA in the feces on day 14 post-infection. Thus, the physical properties of LAB affect their efficacy; controlling their water dispersibility can improve their effectiveness.
\end{abstract}

Keywords: lactic acid bacteria; enterococcus faecalis; dispersion; viral infection; particle size; Peyer's patch

\section{Introduction}

Lactic acid bacteria (LAB) play an important role in various fermentation processes. In his book "Essais Optimistes [1]," the Russian microbiologist Metchnikov advocated the consumption of yogurt to increase life expectancy. This led to a flurry of research on the health benefits of LAB. In recent years, many health benefits have been reported, including improved gut microbiota $[2,3]$ and biological defense $[4,5]$ and anti-allergenic $[6,7]$ and anti-tumorigenic $[8,9]$ effects. The isolation and cultivation of $\mathrm{LAB}$ has made $\mathrm{LAB}$ consumption convenient. The active ingredients present in $\mathrm{LAB}$, including lipoteichoic acid [10] and nucleic acid [11], are involved in modulating the immune response. $\mathrm{LAB}$ are used in food supplements, beverages, confectionery, cereals, and others. They are also consumed as powders. As the market for LAB has grown, research, and development has increased and various kinds of LAB, such as anti-obesity [12] and antiviral [13], have been developed. However, reports evaluating and verifying $L A B$ powder raw materials produced in a factory are scarce. We consider that there is a difference in physical properties, especially dispersion, between factory-produced LAB powder and lab-prepared LAB powder, based on processes such as thermal history and powderization. Studies have reported that the mechanism by which LAB improve the immune response includes LAB being taken up through the Peyer's patches into the 
intestinal tract, phagocytosed by antigen-presenting cells, such as dendritic cells and macrophages $[14,15]$, and recognized by PRRs, such as toll-like receptors, nucleotide binding oligomerization domain-like receptors (NLRs) and retinoic acid inducible gene-like receptors (RLRs) to produce immune-related substances, such as cytokines [16]. LAB are taken up by the $\mathrm{M}$ cells that are scattered on the Peyer's patches, but if LAB aggregate and become larger than $\mathrm{M}$ cells, they are difficult to take up physically. When we checked some LAB materials, we found that LAB were agglomerated, which is common in powdered materials. Therefore, we resuspended the LAB before and after powderization in distilled water and compared their physical properties with the distribution of particle size to investigate whether the effect of the difference in the LAB species or powderization was due to the difference in the species. The mean particle size of LAB before powderization was smaller than that after powderization and bacteria aggregated after powderization. This may lead to a loss of the beneficial effects of LAB on health. We prepared a non-agglomerating LAB powder by dispersing bacteria in a high-pressure homogenizer and adding dextrin as a vehicle. Then, LAB powders with higher and lower number of aggregates were compared. Water dispersibility was analyzed by a laser diffraction particle size analyzer, uptake from mouse Peyer's patches was observed under a microscope, and the protective effect of LAB on viral infection [17-21], which is also the main health effect of LAB, was compared in a mouse influenza infection model.

\section{Materials and Methods}

\subsection{Sample Preparation and Particle Size Measurement}

Enterococcus faecalis KH2 (International Patent Organism Depositary, Japan; number NITE P-14444; GenBank Accession number, AB534553) was stored at Bio-Lab Co., Ltd. LAB were grown aerobically overnight at $37^{\circ} \mathrm{C}$ in MRS broth (Difco, Detroit, MI, USA) and washed with distilled water, followed by centrifugation at 10,000 $\times \mathrm{g}$ for $3 \mathrm{~min}$. The suspension of bacteria in distilled water (20-30 mg (wet bacteria weight)/mL) was heated at $105{ }^{\circ} \mathrm{C}$ for $30 \mathrm{~min}$ using an autoclave (HV-25 II LB; Hirayama Manufacturing Corp., Saitama, Japan). The untreated LAB powder was designated "non-treated LAB: n-LAB." To increase the water dispersibility of the prepared LAB, the sample was treated with a high-pressure homogenizer (ECONIZER LABO-01; Sanmaru Machinery Co., Ltd. Shizuoka, Japan) at 15 MPa and an equal amount of dextrin (NSD300; San-ei Sucrochemical Co., Ltd. Aichi, Japan) was added. The powdered sample was designated "dispersed LAB: d-LAB." A spray dryer (ADL311S-A; Yamato Scientific Co., Ltd. Tokyo, Japan) was used to powderize the samples. Each sample was diluted with distilled water to a concentration of $10 \mathrm{mg} / \mathrm{mL}$, and particle size distribution was measured using a laser diffraction particle size analyzer (SALD-2300; Shimadzu Corporation, Kyoto, Japan) to calculate average and median particle sizes.

\subsection{The State of LAB in Mouse Peyer's Patches}

LAB was diluted with distilled water to $25 \mathrm{mg} / \mathrm{mL}$ and Cy3 (Amersham Cy3 Mono-Reactive Dye Pack, GE Healthcare, Chicago, USA) was added to reach a final concentration of $0.6 \mathrm{mg} / \mathrm{mL}$ and incubated for $2 \mathrm{~h}$ in the dark. Then, the samples were centrifuged at 3,000 rpm for $15 \mathrm{~min}$ and washed with phosphate-buffered saline (PBS)(-). Subsequently, PBS(-) was added to the sample for administration. Male specific pathogen-free Slc:ddY mice (6 weeks old, 16-18 g) were obtained from Tokyo Laboratory Animals Science (Tokyo, Japan). A 100-fold diluted sample was injected into the intestines of mice fasted overnight and incubated for $1 \mathrm{~h}$ for the loop assay. After the intestines were collected, actin was stained with phalloidin (Alexa Fluor ${ }^{\mathrm{TM}} 488$ Phalloidin, Thermo Fisher Scientific, Waltham, MA, USA) and nuclei were stained with DAPI (Thermo Fisher Scientific, Waltham, MA, USA) for $1 \mathrm{~h}$. The stained small intestine was observed under a fluorescence microscope (OPTIPHOTO, NIKON, Tokyo, Japan) or confocal laser scanning microscope (LSM 5EXCITER, ZEISS, Jena, Germany).

\subsection{IL-12 Production by Mouse Splenocytes}


The LAB suspension was added at a final concentration of $1 \mu \mathrm{g} / \mathrm{mL}$ (culture medium, RPMI1640, Wako, Osaka, Japan) to six wells of a 96-well cell culture plate, seeded with mouse splenocytes collected from BALB/c mice (8 to 9 weeks old) obtained from CLEA Japan (Tokyo, Japan). The mixtures of mouse cells and bacteria were cultured in a humidified $5 \% \mathrm{CO}_{2}$ incubator at $37^{\circ} \mathrm{C}$. After incubation for $24 \mathrm{~h}$, the culture supernatants of the mixtures were collected to measure the concentration of IL-12 by enzyme-linked immunosorbent assay (ELISA). The reagents used for ELISA included a primary antibody (purified anti-mouse IL-12 [p70] antibody, BioLegend Inc., San Diego, CA, USA), secondary antibody (Biotin anti-mouse IL-12/IL-23 p40 antibody; BioLegend), blocking reagent (Block Ace Powder, KAC Co., Ltd., Kyoto, Japan), capture antibody (HRP Avidin, BioLegend), substrate (tetramethylbenzidine, Sigma-Aldrich, St. Louis, MO, USA), and standards (Recombinant Mouse IL-12 [p70] [ELISA Std.], BioLegend), and IL-12 levels were measured using sandwich ELISA [24].

\subsection{Model of Mouse Influenza Infection}

Female, specific pathogen-free BALB/c mice (5-6 weeks old, 16-18 g) were obtained from Japan SLC (Shizuoka, Japan). All experiments were conducted in accordance with the animal experimentation guidelines of Chubu University and permitted by the Animal Care Committee of Chubu University (Permission number: 3010057). No side effects of drugs were detected throughout the experiments. Mice were intranasally infected with influenza A virus (A/NWS/33, H1N1 subtype) [25] at $2 \times 10^{4}$ plaque-forming units $(\mathrm{PFU}) / 50 \mu \mathrm{L}$ per mouse $(\mathrm{n}=10)$ on day $0 . \mathrm{n}$-LAB $(5 \mathrm{mg} / \mathrm{mouse} / \mathrm{d})$ and d-LAB (as dextrin was mixed with $\mathrm{LAB}$ in equal amounts, we doubled the dose to 10 $\mathrm{mg} / \mathrm{mouse} / \mathrm{d}$ ) were suspended in distilled water. Oseltamivir phosphate (OSL; $0.2 \mathrm{mg} / \mathrm{mouse} / \mathrm{d}$ ) was used as a positive control for antiviral effects and dissolved in distilled water. LAB, d-LAB, or OSL was given by oral administration two times per day, from $7 \mathrm{~d}$ before viral inoculation to $14 \mathrm{~d}$ after inoculation. The control mice were administered orally with vehicle (distilled water) alone. Because influenza virus (IFV) infection causes a reduction in body weight [26,27], mice of each treatment group were weighed daily for $14 \mathrm{~d}$, beginning on the day of IFV inoculation (designated day 0). Lung samples and bronchoalveolar lavage fluid (BALF) were collected from each group on days 3 and 14, and blood and fecal samples were collected on day 14 (Fig. 1). Lung samples were sonicated for $10 \mathrm{~s}$ after the addition of $10 \mu \mathrm{L}$ PBS per mg of lung tissue and centrifuged at 1,500 rpm for $30 \mathrm{~min}$ to separate the supernatants, which were stored at $-80^{\circ} \mathrm{C}$. BALFs were collected after four washes with $0.8 \mathrm{~mL}$ ice-cold PBS via a tracheal cannula and centrifuged at 1,500 rpm for $10 \mathrm{~min}$; the supernatants were stored at $-80{ }^{\circ} \mathrm{C}$. Blood samples were centrifuged at 3,000 rpm for $10 \mathrm{~min}$, and the sera were stored at $-20^{\circ} \mathrm{C}$. Fecal extracts were prepared by adding PBS at $10 \mu \mathrm{L}$ per mg of feces. The amount of virus in the lung and BALF samples collected on day 3 post-infection was quantified using the plaque assays on Madin-Darby canine kidney (MDCK) cell monolayers. Sera and BALFs were subjected to neutralizing antibody titer assays using the $50 \%$ plaque reduction method, as described [28,29]. BALFs and fecal extracts were assessed for mucosal virus-specific IgA levels by ELISA, as described [30].

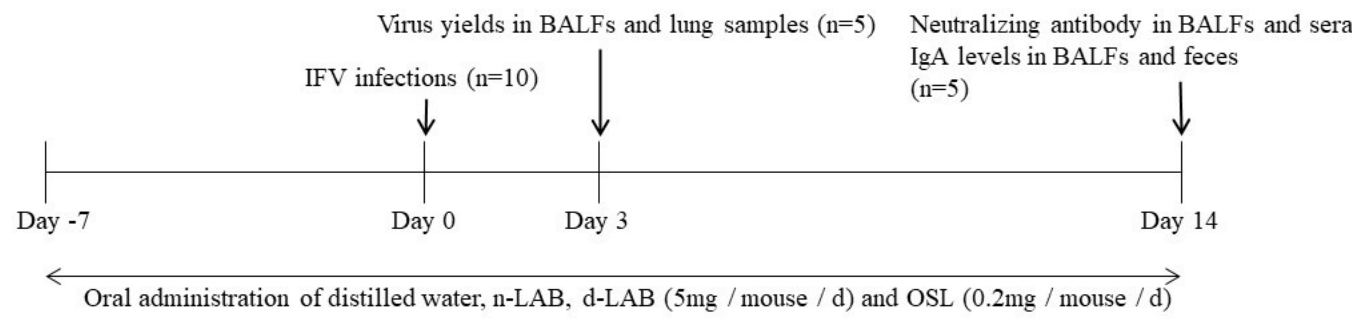

Figure 1. Experimental procedure of influenza virus infection. Mice in the control, $L A B, d-L A B$, and OSL groups were administered distilled water, LAB, and d-LAB ( $5 \mathrm{mg} / \mathrm{d}$, two doses per day) and OSL (0.2 mg/d, two doses per day), respectively, during the study period (days -7 to 14 ). Mice were intranasally infected with IFV on day 0 . On day 3 after IFV infection, five mice from each group were euthanized to quantify virus loads in BALFs and lungs. Five mice were euthanized for measuring neutralizing antibody and IgA levels on day 14. BALF, bronchoalveolar lavage fluid; d-LAB, 
dispersed lactic acid bacteria; IFV, influenza A virus; n-LAB, non-treated lactic acid bacteria; OSL, oseltamivir phosphate.

\subsection{Statistical Analysis}

The effects of the drugs were analyzed by one-way analysis of variance, and correction for multiple comparisons was done by Tukey's multiple comparison test. A $p$ value of $<0.05$ was considered to be significant.

\section{Results}

\subsection{Particle Size of $n-L A B$ and $d-L A B$}

Figure $2 \mathrm{~A}$ shows the particle size distribution of $\mathrm{LAB}$ that was washed with distilled water and powdered using a spray dryer. Figure $2 B$ shows the particle size distribution of $d$-LAB that was washed with distilled water, treated with a high-pressure homogenizer, and powdered with an equal amount of dextrin. The mean and median particle sizes of n-LAB and d-LAB are shown in Table 1. n-LAB and d-LAB were found to be more abundant around 55 and $0.7 \mu \mathrm{m}$ in particle size. The mean particle size of $\mathrm{d}-\mathrm{LAB}$ was smaller, $0.679 \mu \mathrm{m}$ compared to $35.454 \mu \mathrm{m}$ for $\mathrm{n}-\mathrm{LAB}$; the median was $0.633 \mu \mathrm{m}$ for d-LAB compared to $40.761 \mu \mathrm{m}$ for n-LAB (Table 1).
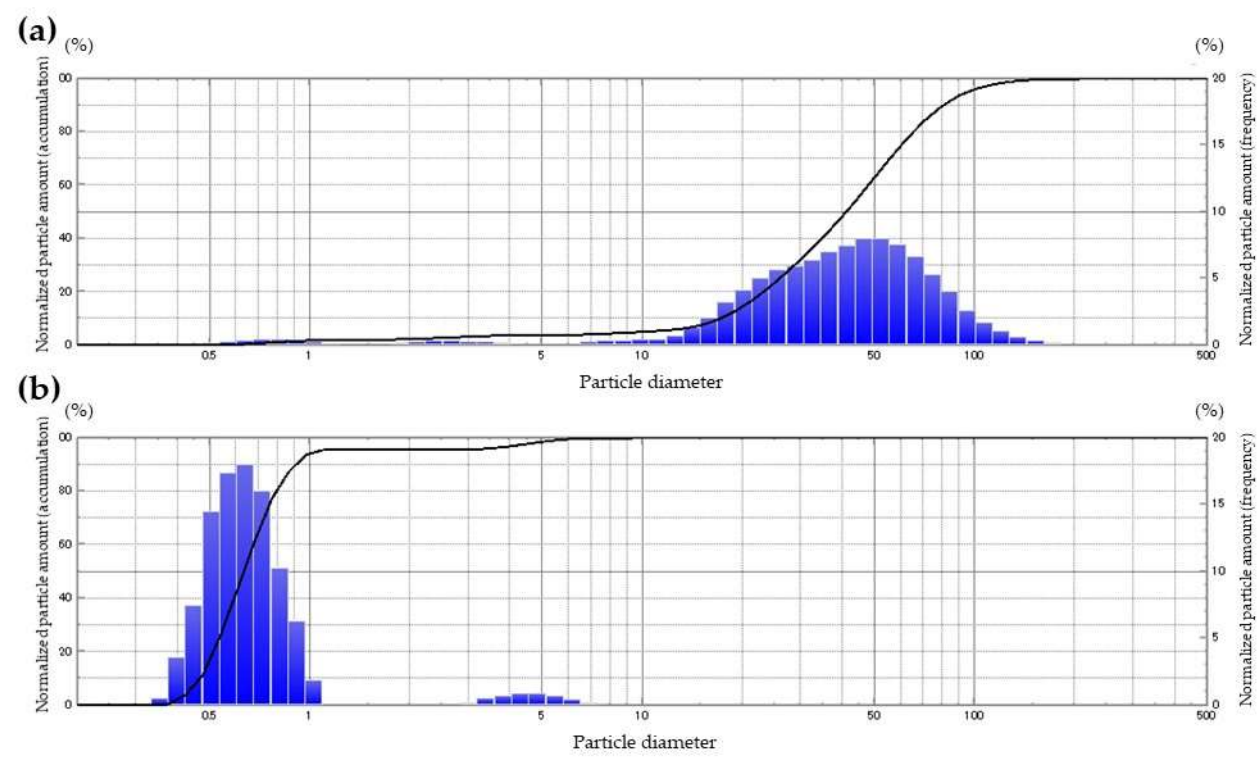

Figure 2. Measurement of $n-L A B$ and $d-L A B$ using a laser diffraction particle size analyzer (SALD-2300). n-LAB (a) and d-LAB (b) were suspended in distilled water and the relative particle mass (frequency and integration) was measured using a laser diffraction particle size analyzer. $\mathrm{d}-\mathrm{LAB}$, dispersed lactic acid bacteria; $\mathrm{n}-\mathrm{LAB}$, non-treated lactic acid bacteria; $\mathrm{n}=3$.

Table 1. Measurement of n-LAB and d-LAB using a laser diffraction particle size analyzer

particle sizes $(\mu \mathrm{m})$ 


\begin{tabular}{ccccc} 
& Mean & \pm & SD & Median \\
\hline n-LAB & 35.454 & \pm & 0.378 & 40.761 \\
d-LAB & 0.679 & \pm & 0.203 & $0.633^{* *}$ \\
\hline
\end{tabular}

The n-LAB (a) or d-LAB (b) were suspended in distilled water and particle sizes (mean and median) were measured using a laser diffraction particle size analyzer (SALD-2300). d-LAB, dispersed lactic acid bacteria; $\mathrm{n}-\mathrm{LAB}$, non-treated lactic acid bacteria; $\mathrm{n}=3$; ${ }^{* *} \mathrm{p}<0.01$ vs. $\mathrm{n}-\mathrm{LAB}$.

\subsection{Observation of Mice Peyer's Patches After $n-L A B$ and d-LAB Administration}

n-LAB was not visible on Peyer's patches but was observed on the mucosa around the Peyer's patches (Fig. 3A). n-LAB was in an agglomerated state. In contrast, d-LAB was observed on the surface of the Peyer's patches (Fig. 3B). Furthermore, cLSM was used to confirm the underlying layer of the Peyer's patches upon d-LAB administration and bacterial uptake into the body was present (Fig. 3C).
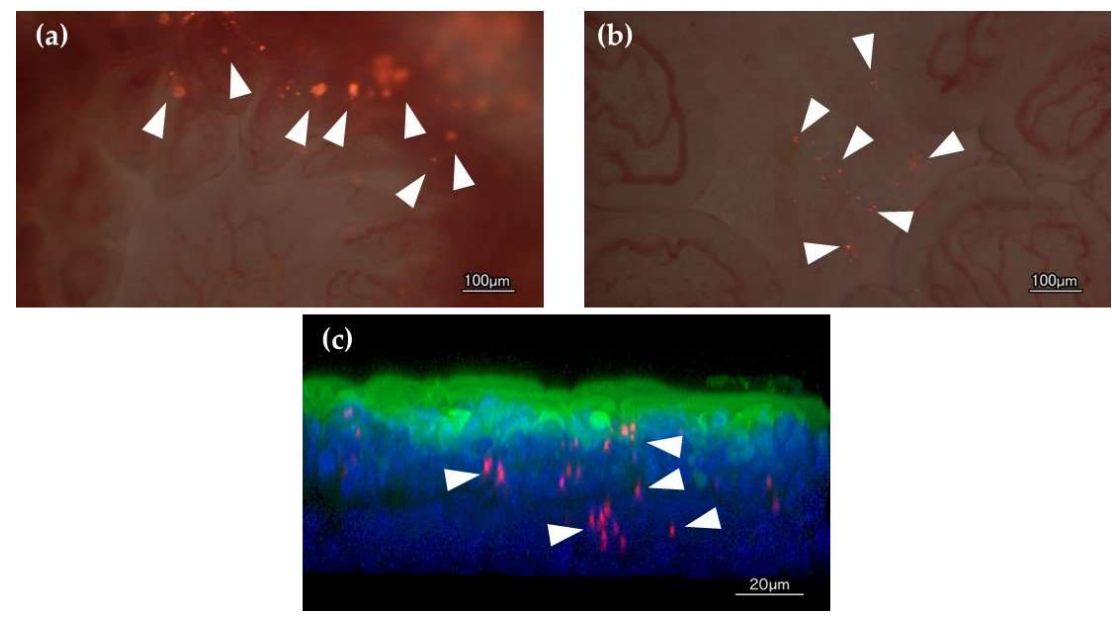

Figure 3. Microscopy images of the Peyer's patch in mice after LAB and d-LAB administration and Peyer's plate images after d-LAB administration with cLSM. n-LAB (a) or d-LAB (b) stained with Cy3 and Peyer's patches were imaged with a fluorescence microscope. The uptake of d-LAB by Peyer's patches after d-LAB administration was imaged with CLSM (c).The white triangular arrow shows the bacteria. cLSM, confocal laser scanning microscopy; d-LAB, dispersed lactic acid bacteria; n-LAB, non-treated lactic acid bacteria.

\subsection{Effects of $n-L A B$ and $d-L A B$ on IL-12 Production in Mouse Splenocytes}

We compared IL-12 production after $n-L A B$ and $d-L A B$ administration using mouse splenocytes and found that d-LAB was significantly higher than n-LAB (Fig. 4). 


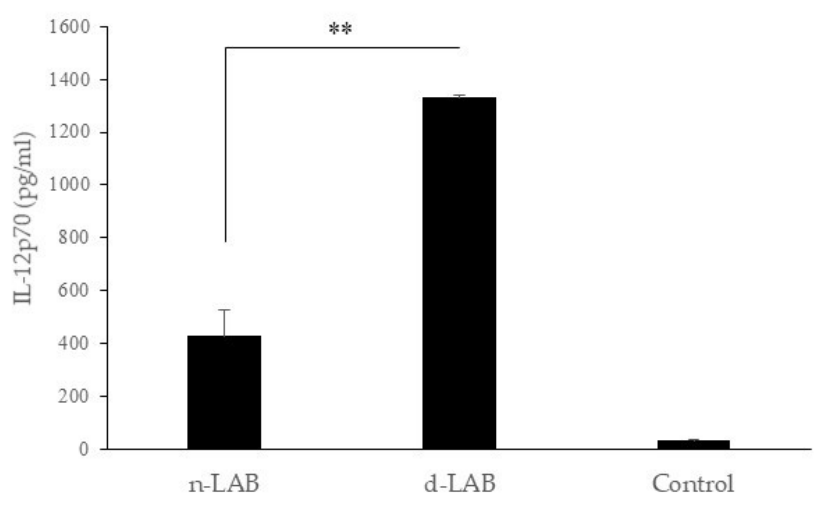

Figure 4. Effect of ribonuclease treatment after $n-L A B$ and d-LAB administration on IL-12 production in mouse splenocytes. $n$-LAB and d-LAB co-cultured with mouse splenocytes for $24 \mathrm{~h}$. IL-12 concentration in the culture supernatant was measured by enzyme-linked immunosorbent assay (ELISA). Control, culture medium only; d-LAB, dispersed lactic acid bacteria; n-LAB, non-treated lactic acid bacteria. Each value is presented as the mean $\pm S D ; n=6 ;{ }^{* *} p<0.01$ vs. $n-L A B$.

\subsection{Effects of $n-L A B$ and $d-L A B$ on IVF Infection in Mice}

The effects of n-LAB and d-LAB on the change in body weight of mice infected with IFV were examined (Fig. 5). The control, n-LAB, and d-LAB groups showed approximately 15.9\%, 14.9\%, and $14.4 \%$ loss, respectively, on day 7 post-infection. Although no significant difference was observed between the n-LAB and d-LAB groups, d-LAB suppressed weight loss slightly more than n-LAB. Thereafter, mice gradually gained body weight, and the mice in the d-LAB group returned to their pre-infection body weights on day 12 post-infection.

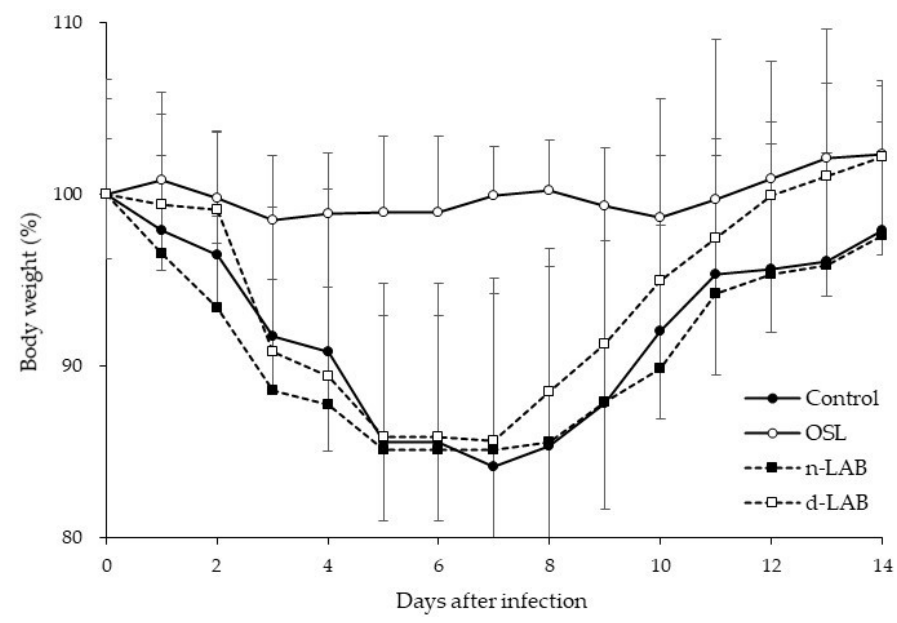

Figure 5. Body weight change in mice infected with IFV. IFV-infected mice were orally administered distilled water (control, filled circle), $0.2 \mathrm{mg} / \mathrm{d}$ of oseltamivir (OSL, white circle), $5 \mathrm{mg} / \mathrm{d}$ of non-treated lactic acid bacteria (n-LAB, filled square), and $5 \mathrm{mg} / \mathrm{d}$ of dispersed lactic acid bacteria (d-LAB, white square) from $7 \mathrm{~d}$ before viral infection to $14 \mathrm{~d}$ post-infection. Body weights are relative to those on the day of viral infection (day 0), which was set as $100 \%$. Each value is presented as the mean $\pm S D ; n=5$; IFV, influenza A virus.

Virus yields in the BALF and lung of IFV-infected mice on day 3 post-infection are shown in Figures $6 \mathrm{~A}$ and $6 \mathrm{~B}$, respectively. Oral administration of $\mathrm{n}-\mathrm{LAB}$ and $\mathrm{d}-\mathrm{LAB}$ significantly reduced the virus load in BALFs $(p<0.01)$ and lungs $(p<0.05)$ compared with the control group. The d-LAB group had a significantly lower viral load than the n-LAB group in the BALFs $(p<0.05)$. Virus loads in the OSL group were markedly low, as shown in Figure 6A, B. 
(a)

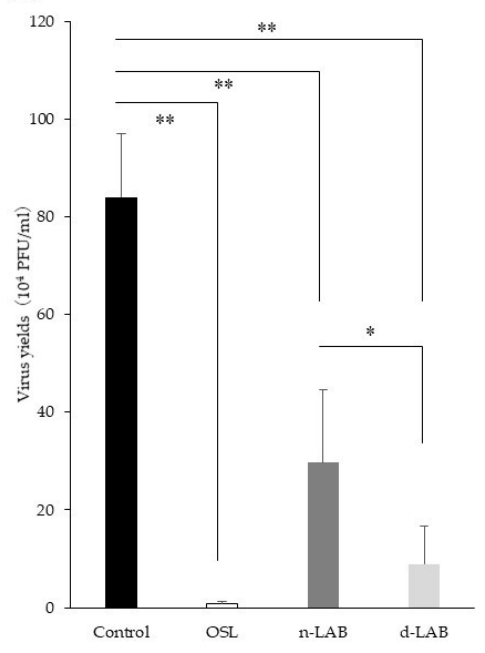

(b)

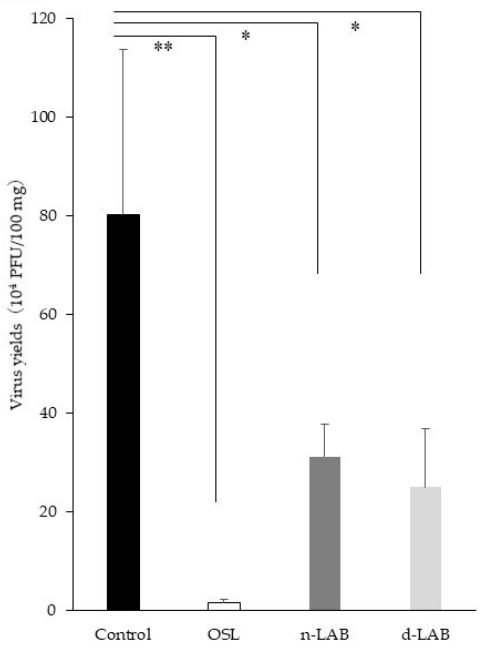

Figure 6. Effect of LAB or d-LAB administration on virus load in mice. Virus yield in BALFs (a) and lung samples (b) were measured using a plaque assay on day 3 post-infection. Each value is presented as the mean $\pm \mathrm{SD} ; \mathrm{n}=5 ;{ }^{* *} \mathrm{p}<0.01 ;{ }^{*} \mathrm{p}<0.05$. BALF, bronchoalveolar lavage fluid; $\mathrm{d}-\mathrm{LAB}$, dispersed lactic acid bacteria; n-LAB, non-treated lactic acid bacteria; OSL, oseltamivir; PFU, plaque-forming units.

Figures 7A, B show the effects of $n-L A B$ and $d-L A B$ on the neutralizing antibody response to IFV in BALFs (Fig. 7A) and sera (Fig. 7B) at day 14 post-infection. The antibody titers of BALFs in the mice administered with $n-L A B$ or $d-L A B$ were significantly higher than those in the control group. Moreover, it was significantly higher in the d-LAB than the n-LAB group $(p<0.05)$. By contrast, the antibody titer in the $d-L A B$ group was significantly higher $(p<0.01)$ than that in the control group.

To elucidate whether n-LAB and d-LAB stimulate the local immune response in mice, the levels of IFV-specific IgA in BALFs and feces were determined at day 14 post-infection (Fig. 7C, D). IgA production in the $d-L A B$ group was significantly higher than the control group $(p<0.01)$. The IgA levels in the feces were significantly higher in the d-LAB group than the $n-L A B$ group to $(p<0.05)$. 
(a)

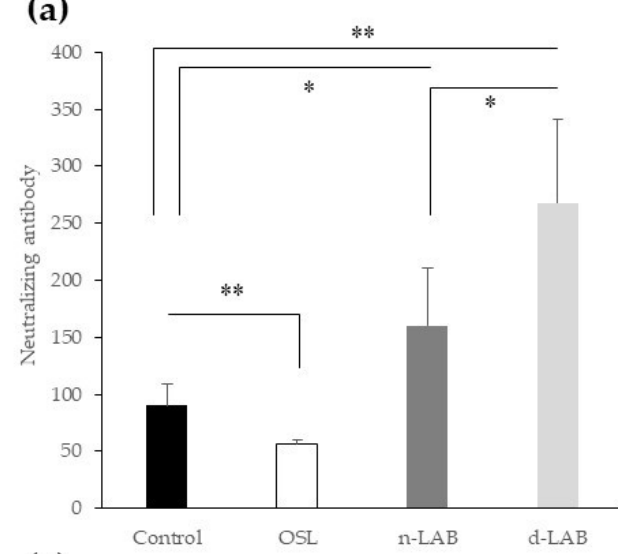

(c)

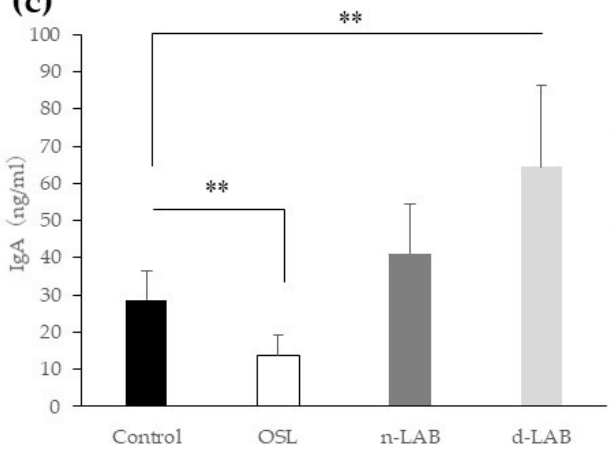

(b)

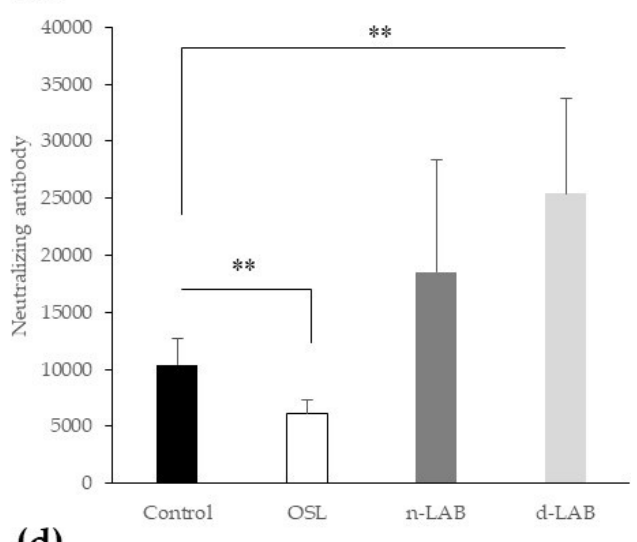

(d)

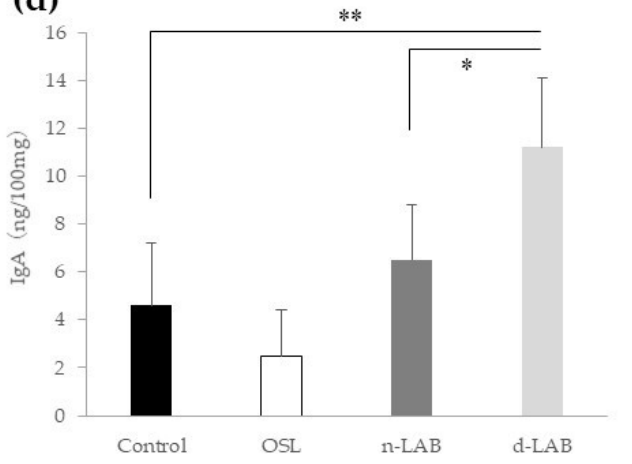

Figure 7. Effects of $\mathrm{n}-\mathrm{LAB}$ or $\mathrm{d}-\mathrm{LAB}$ administration on the neutralizing antibody titer and production of IFV-specific IgA in mice. The titer of the virus-neutralizing antibody is presented as the reciprocal of the dilution of BALFs (a) and sera (b) that reduced the plaque number to a level below $50 \%$ of that seen in the virus control. The IFV-specific IgA levels in BALFs (c) and feces (d) were determined by ELISA. Each value is presented as the mean $\pm \mathrm{SD} ; \mathrm{n}=5 ;{ }^{* *} \mathrm{p}<0.01 ;{ }^{*} \mathrm{p}<0.05$. BALF, bronchoalveolar lavage fluid; IFV, influenza A virus; d-LAB, dispersed lactic acid bacteria; n-LAB, non-treated lactic acid bacteria; OSL, oseltamivir.

\section{Discussion}

When cultured LAB are washed and dried into powder, the bacteria adhere to each other and form aggregates (Table 1, Fig. 2). One possible cause is that the polysaccharides produced by LAB and the capsules present on the surface of the bacteria may help in bonding during drying. Furthermore, it has been reported that bacterial surface proteins [31] are involved in charge stability and that non-specific electrostatic effects may be a factor in adhesion. LAB were reported to adhere to polysaccharides, such as xylan and mucin, by surface layer protein action [32], and it is natural for bacteria to adhere to a variety of substrates to survive. Thus, polysaccharide-producing LAB may stick to each other. Further, powderization may strengthen the binding. However, in consideration of quality and cost, it is desirable to powderize LAB for distribution, but if LAB agglomerate with each other by powderization (Fig. 2A), the product may be affected. Therefore, we developed a LAB powder ( $\mathrm{d}-\mathrm{LAB}$ ) with less agglomerates, by homogenizing the culture and adding dextrin to the powder to prevent the agglomerates from re-agglomerating (Fig. 2B). d-LAB was measured using a laser diffraction particle size analyzer and average particle size was $0.679 \mu \mathrm{m}$, indicating few bacterial aggregates. Then, $\mathrm{n}-\mathrm{LAB}$, with several bacteria aggregates, and d-LAB, with excellent water dispersibility and fewer aggregates, were administered to mice and observed in the vicinity of the Peyer's patches in the small intestine. n-LAB failed to reach the Peyer's patches and drifted on the mucus covering the Peyer's patches, whereas d-LAB reached the Peyer's patches. This difference may be due to the presence of membrane-tethered mucin in the intestinal cells. [33,34]. We think that $\mathrm{n}$-LAB, which has many bacteria aggregates of about $50 \mu \mathrm{m}$ in size (Fig. $3 \mathrm{~A}$ ), is physically prevented 
from contacting the intestinal tract by mucin, whereas $\mathrm{d}-\mathrm{LAB}$, which has fewer aggregates, can pass through mucin and reach the Peyer's patches (Fig. 3B, C). Furthermore, larger aggregates of LAB were found to reduce the immune response to phagocytosis by macrophages and dendritic cells (Fig. 4). These results suggest that $\mathrm{LAB}$ aggregation may not only reduce their uptake from $\mathrm{M}$ cells in Peyer's patches, but also affect their phagocytosis and decrease the immune response of $L A B$; therefore, we compared n-LAB and d-LAB in a mouse influenza infection model. n-LAB differed significantly from d-LAB in IFV yield of BALFs at $3 \mathrm{~d}$ after infection (Fig. 6) and in neutralizing antibody titers of BALFs and IFV-specific IgA in feces at $14 \mathrm{~d}$ after infection (Fig. 7). Although the difference was not significant, n-LAB showed almost the same transition in body weight as control, whereas d-LAB showed rapid weight recovery after $7 \mathrm{~d}$ of infection and returned to pre-infection weight by day 12 (Fig. 5). The results of this study show that the effectiveness of LAB decreases when there are many aggregates of LAB. The effects of Lactobacillus species, strains [35], culture methods [36], and use [37] have been studied extensively. However, there are few reports of changes in the physical properties of LAB during powderization that affect their health benefits. To make $\mathrm{LAB}$ use effective, we recommend studying and verifying the properties of LAB at the consumer stage. Therefore, not only will we evaluate the LAB prepared in our laboratory, but we will also study LAB in a form close to the final product to confirm whether the effectiveness of the LAB has been lost. We will continue to develop better $\mathrm{LAB}$ and improve their quality.

\section{Conclusions}

In this study, it was found that $\mathrm{LAB}$ could not reach the Peyer's patches through the intestinal mucosa because of the formation of aggregates when $\mathrm{LAB}$ were powdered, although this was true for all LAB (Fig. 8A). n-LAB were found to have an effect on the efficacy (protection against viral infection). Therefore, we developed a LAB powder (d-LAB) with less agglomerates by treating it with a high-pressure homogenizer and adding an excipient to prevent agglomeration. When the d-LAB were administered to mice, they were able to pass through the intestinal mucosa and reach the Peyer's patches because of the improved water dispersibility of the bacteria (Fig. 8B). Thus, the effectiveness of the LAB with improved dispersibility was higher. These results indicate that differences in water dispersibility of LAB has an effect on protection against IFV infection. Therefore, we can increase the health benefits of LAB by improving the dispersibility of LAB that have low water dispersibility.
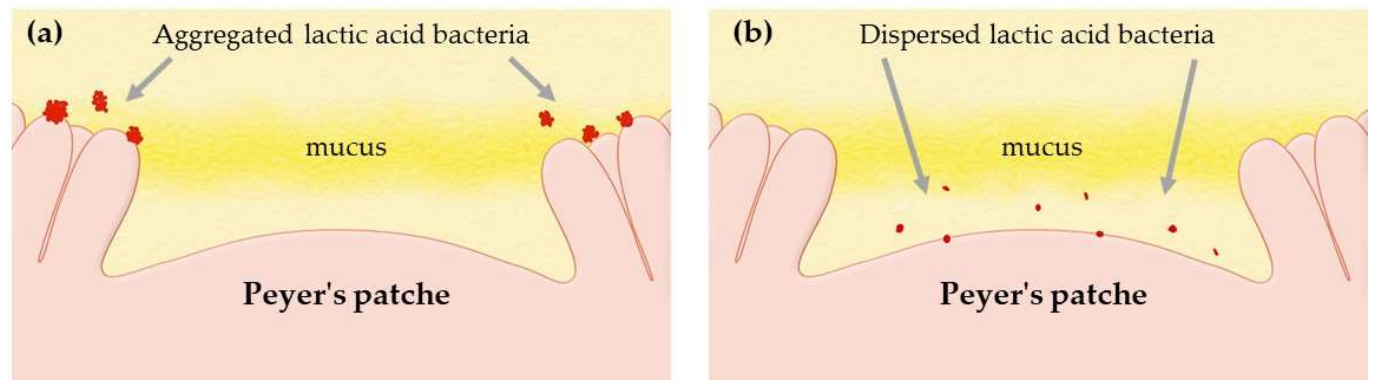

Figure 8. Image of aggregated lactic acid bacteria or dispersed lactic acid bacteria in contact with the small intestinal Peyer's patches. Aggregated lactic acid bacteria could not reach the Peyer's patches because of large particle size, which is blocked by mucus (a). Dispersed lactic acid bacteria were small particle size and can pass through mucus to reach the Peyer's patches (b). 
Author Contributions: Conceptualization, T.W and K.H.; methodology, T.W., K.H., I.T. and M.O.; software, T.W.; validation, K.H.; formal analysis, K.H.; investigation, T.W.; resources, K.H., T.K. and T.K..; data curation, T.W. and K.H.; writing-original draft preparation, T.W.; writing-review and editing, K.H. and T.K.; visualization, T.W. and I.T.; supervision, T.W., K.H. and T.K. All authors have read and agreed to the published version of the manuscript.

Funding: This research received no external funding.

Acknowledgments: We thank Ms. Kazumi Shimizu (Non-Profit Organization, The Japanese Association of Clinical Research on Supplements) and Ms. Yuriko Namatame (Bio-Lab Co., Ltd.) for skillful technical assistance and valuable discussions. The authors would like to thank Enago (www.enago.jp) for the English language review.

Conflicts of Interest: The authors declare no conflict of interest.

\section{References}

1. Metchnikoff E. Essais Optimistes.; A. Maloine: Paris, France, 1907.

2. Fujiwara, S.; Seto, Y.; Kimura, A.; Hashiba, H. Establishment of orally-administered Lactobacillus gasseri SBT2055SR in the gastrointestinal tract of humans and its influence on intestinal microflora and metabolism. J Appl Microbiol. 2001, 90, 343-352.

3. Unno, T.; Choi, JH.; Hur, HG.; Sadowsky, MJ.; Ahn, YT.; Huh, CS.; Kim, GB.; Cha, CJ. Changes in human gut microbiota influenced by probiotic fermented milk ingestion. J Dairy Sci. 2015, 98, 3568-3576.

4. Reid, G.; Bruce, AW.; McGroarty, JA.; Cheng, KJ.; Costerton, JW. Is there a role for lactobacilli in prevention of urogenital and intestinal infections? Clin Microbiol Rev. 1990, 3, 335-344.

5. Asahara, T.; Shimizu, K.; Nomoto, K.; Hamabata, T.; Ozawa, A.; Takeda, Y. Probiotic bifidobacteria protect mice from lethal infection with Shiga toxin-producing Escherichia coli O157:H7. Infect Immun. 2004, 72, 2240-2247.

6. Cross, ML.; Stevenson, LM.; Gill, HS. Anti-allergy properties of fermented foods: an important immunoregulatory mechanism of lactic acid bacteria? Int Immunopharmacol. 2001, 1, 891-901.

7. Zhang, Q.; Ai, C.; Wang, G.; Liu, X.; Tian, F.; Zhao, J.; Zhang, H.; Chen, YQ.; Chen, W. Oral application of lactic acid bacteria following treatment with antibiotics inhibits allergic airway inflammation. J Appl Microbiol. 2015, 119, 809-817.

8. Tsukahara, T.; Nakamura, SI.; Romero-Pèrez, GA.; Ohwaki, M.; Yanagisawa, T.; Kan, T. Stimulation of murine cell-mediated immunity by dietary administration of a cell preparation of Enterococcus faecalis strain KH-2 and its possible activity against tumour development in mice. Biosci Microbiota Food Health. 2018, 37, 49-57.

9. Banna, GL.; Torino, F.; Marletta, F.; Santagati, M.; Salemi, R.; Cannarozzo, E.; Falzone, L.; Ferraù, F.; Libra M. Lactobacillus rhamnosus GG: An Overview to Explore the Rationale of Its Use in Cancer. Front Pharmacol. 2017, 8, 603.

10. Mizuno, H.; Arce, L.; Tomotsune, K.; Albarracin, L.; Funabashi, R.; Vera, D.; Islam, MA.; Vizoso-Pinto, MG.; Takahashi, H.; Sasaki, Y.; Kitazawa, H.; Villena, J. Lipoteichoic Acid Is Involved in the Ability of the Immunobiotic Strain Lactobacillus plantarum CRL1506 to Modulate the Intestinal Antiviral Innate Immunity Triggered by TLR3 Activation. Front Immunol. 2020, 11, 571.

11. Bouladoux, N.; Hall, JA.; Grainger, JR.; dos, Santos, LM.; Kann, MG.; Nagarajan, V.; Verthelyi, D.; Belkaid, 
Y. Regulatory role of suppressive motifs from commensal DNA. Mucosal Immunol. 2012, 5, 623-34.

12. Ji, Y.; Chung, YM.; Park, S.; Jeong, D.; Kim, B.; Holzapfel, WH. Dose-dependent and strain-dependent anti-obesity effects of Lactobacillus sakei in a diet induced obese murine model. PeerJ. 2019, 7, e6651.

13. Kitazawa, H.; Villena, J. Modulation of Respiratory TLR3-Anti-Viral Response by Probiotic Microorganisms: Lessons Learned from Lactobacillus rhamnosus CRL1505. Front Immunol. 2014, 5, 201.

14. Yanagihara, S.; Kato, S.; Ashida, N.; Yamamoto, N. Lactobacillus acidophilus CP23 with weak immunomodulatory activity lacks anchoring structure for surface layer protein. J Biosci Bioeng. 2015, 119, 521-525.

15. Savidge, TC.; Smith, MW.; James, PS.; Aldred, P. Salmonella-induced M-cell formation in germ-free mouse Peyer's patch tissue. Am J Pathol. 1991, 139, 177-184.

16. Akira, S.; Takeda, K.; Kaisho, T. Toll-like receptors: critical proteins linking innate and acquired immunity. Nat Immunol. 2001, 2, 675-680.

17. Hori, T.; Kiyoshima, J.; Shida, K.; Yasui, H. Effect of intranasal administration of Lactobacillus casei Shirota on influenza virus infection of upper respiratory tract in mice. Clin Diagn Lab Immunol. 2001, 8, 593-597.

18. Youn, HN.; Lee, DH.; Lee, YN.; Park, JK.; Yuk, SS.; Yang, SY.; Lee, HJ.; Woo, SH.; Kim, HM.; Lee, JB.; Park, SY.; Choi, IS.; Song, CS. Intranasal administration of live Lactobacillus species facilitates protection against influenza virus infection in mice. Antiviral Res. 2012, 93, 138-143.

19. Harata, G.; He, F.; Hiruta, N.; Kawase, M.; Kubota, A.; Hiramatsu, M.; Yausi, H. Intranasal administration of Lactobacillus rhamnosus GG protects mice from H1N1 influenza virus infection by regulating respiratory immune responses. Lett Appl Microbiol. 2010, 50, 597-602.

20. Kechaou, N.; Chain, F.; Gratadoux, JJ.; Blugeon, S.; Bertho, N.; Chevalier, C.; Le, Goffic R.; Courau, S.; Molimard, P.; Chatel, JM.; Langella, P.; Bermúdez-Humarán, LG. Identification of one novel candidate probiotic Lactobacillus plantarum strain active against influenza virus infection in mice by a large-scale screening. Appl Environ Microbiol. 2013, 79, 1491-1499.

21. Lee, YN.; Youn, HN.; Kwon, JH.; Lee, DH.; Park, JK.; Yuk, SS.; Erdene-Ochir, TO.; Kim, KT.; Lee, JB.; Park, SY.; Choi, IS.; Song, CS. Sublingual administration of Lactobacillus rhamnosus affects respiratory immune responses and facilitates protection against influenza virus infection in mice. Antiviral Res. 2013, 98, 284-290.

22. Punyashthiti, K.; Finkelstein, RA. Enteropathogenicity of Escherichia coli. I. Evaluation of mouse intestinal loops. Infect Immun. 1971, 4, 473-478.

23. Owen, RL.; Pierce, NF.; Apple, RT.; Cray, WC Jr. M cell transport of Vibrio cholerae from the intestinal lumen into Peyer's patches: a mechanism for antigen sampling and for microbial transepithelial migration. J Infect Dis. 1986, 153, 1108-1118.

24. Kragstrup, TW.; Vorup-Jensen, T.; Deleuran, B.; Hvid, M. A simple set of validation steps identifies and removes false results in a sandwich enzyme-linked immunosorbent assay caused by anti-animal $\operatorname{IgG}$ antibodies in plasma from arthritis patients. Springerplus. 2013, 2, 263.

25. Govorkova, EA.; Fang, HB.; Tan, M.; Webster, RG. Neuraminidase inhibitor-rimantadine combinations exert additive and synergistic anti-influenza virus effects in MDCK cells. Antimicrob Agents Chemother. 2004, 48, 4855-4863.

26. Kinoshita, E.; Hayashi, K.; Katayama, H.; Hayashi, T.; Obata, A. Anti-influenza virus effects of elderberry juice and its fractions. Biosci Biotechnol Biochem. 2012, 76, 1633-1638.

27. Hayashi, K.; Narutaki, K.; Nagaoka, Y.; Hayashi, T.; Uesato, S. Therapeutic effect of arctiin and arctigenin in immunocompetent and immunocompromised mice infected with influenza A virus. Biol Pharm Bull. 
2010, 33, 1199-1205.

28. Sasaki, K.; Hayashi, K.; Lee, JB.; Kurosaki, F.; Hayashi, T. Characterization of a novel mutation in NS1 protein of influenza A virus induced by a chemical substance for the attenuation of pathogenicity. PLoS One. 2015, 10, e0121205.

29. Terasawa, M.; Hayashi, K.; Lee, JB.; Nishiura, K.; Matsuda, K.; Hayashi, T.; Kawahara, T. Anti-Influenza A Virus Activity of Rhamnan Sulfate from Green Algae Monostroma nitidum in Mice with Normal and Compromised Immunity. Mar Drugs. 2020, 18, 254.

30. Hayashi, K.; Lee, JB.; Nakano, T.; Hayashi, T. Anti-influenza A virus characteristics of a fucoidan from sporophyll of Undaria pinnatifida in mice with normal and compromised immunity. Microb. Infect. 2013, 15, 302-309.

31. Hynönen, U.; Palva, A. Lactobacillus surface layer proteins: structure, function and applications. Appl Microbiol Biotechnol. 2013, 97, 5225-5243.

32. Saito, K.; Nakamura, T.; Kobayashi, I.; Ohnishi-Kameyama, M.; Ichinose, H.; Kimura, K.; Funane, K. Xylan-mediated aggregation of Lactobacillus brevis and its relationship with the surface properties and mucin-mediated aggregation of the bacteria. Biosci Biotechnol Biochem. 2014, 78, 2120-2127.

33. Ambort, D.; Johansson, ME.; Gustafsson, JK.; Nilsson, HE.; Ermund, A.; Johansson, BR.; Koeck, PJ.; Hebert, H.; Hansson, GC. Calcium and pH-dependent packing and release of the gel-forming MUC2 mucin. Proc Natl Acad Sci U S A. 2012, 109, 5645-5650.

34. Schütte, A.; Ermund, A.; Becker-Pauly, C.; Johansson, ME.; Rodriguez-Pineiro, AM.; Bäckhed, F.; Müller, S.; Lottaz, D.; Bond, JS.; Hansson, GC. Microbial-induced meprin $\beta$ cleavage in MUC2 mucin and a functional CFTR channel are required to release anchored small intestinal mucus. Proc Natl Acad Sci U S A. 2014, 111, 12396-12401.

35. Barache, N.; Belguesmia, Y.; Ladjouzi, R.; Bendali, F.; Drider, D. Clusters of Lactobacillus Strains from Vegetal Origins Are Associated with Beneficial Functions: Experimental Data and Statistical Interpretations. Foods. 2020, 9, 985.

36. Nishimura, J.; Kawai, Y.; Aritomo, R.; Ito, Y.; Makino, S.; Ikegami, S.; Isogai, E.; Saito, T. Effect of Formic Acid on Exopolysaccharide Production in Skim Milk Fermentation by Lactobacillus delbrueckii subsp. bulgaricus OLL1073R-1. Biosci Microbiota Food Health. 2013, 32, 23-32.

37. Bancalari, E.; Castellone, V.; Bottari, B.; Gatti, M. Wild Lactobacillus casei Group Strains: Potentiality to Ferment Plant Derived Juices. Foods. 2020, 9, 985. 